\title{
A atividade de estudo na produção do conhecimento histórico escolar
}

\author{
Learning Activity in the production of schooling historical knowledge
}

Olavo Pereira Soares ${ }^{1}$

\section{RESUMO}

$\mathrm{O}$ texto trata da atividade de estudo e das suas potencialidades nos processos de produção do conhecimento histórico escolar. No primeiro momento, são analisadas três categorias essenciais desta proposta didática: as tarefas de estudo, a motivação e a aprendizagem conceitual. $\mathrm{O}$ referencial teórico sobre tais categorias está baseado em precursores da teoria histórico-cultural e dos pesquisadores que desenvolveram as categorias básicas para a compreensão da atividade de estudo enquanto perspectiva teórico-metodológica para a didática. $\mathrm{Na}$ segunda parte apresenta proposições e princípios que sejam plausíveis de ser recomendados tanto para os professores que atuam nas práticas escolares quanto para as pesquisas que se dedicam ao ensino e a aprendizagem da história na escola. $\mathrm{O}$ artigo destaca que a atividade de estudo é um referencial teórico-metodológico que abre promissoras possibilidades de melhorias qualitativas para a produção do conhecimento histórico escolar.

Palavras-chave: Ensino de história. Atividade de estudo. Desejo e motivação. Aprendizagem conceitual.

\begin{abstract}
The text deals with learning activity and its potentialities in the processes of producing schooling historical knowledge. In the first moment, three essential categories of this didactic proposal are analysed: learning tasks, motivation and conceptual learning. The theoretical framework on such categories is based on precursors of historical-cultural theory and the researchers who developed the basic categories for understanding learning activity as a theoretical-methodological perspective for didactics. In the second part, it presents propositions and principles that are plausible to be recommended both for teachers who work in school practices and for researches dedicated to the teaching and learning of history at school. The article highlights that learning activity is a theoretical-methodological framework that opens up promising possibilities for qualitative improvements for the production of school historical knowledge.
\end{abstract}

\section{Introdução}

A educação escolar se diferencia dos demais processos educativos quando consegue estabelecer o diálogo entre os conceitos formulados na cultura cotidiana com os conceitos científicos. Na vida extraescolar, os alunos atribuem sentidos aos

\footnotetext{
${ }^{1}$ Olavo Pereira Soares - Programa de Pós-graduação em Educação, UNIFAL/MG - Universidade Federal de Alfenas, Minas Gerais, Brasil. ORCID: https://orcid.org/0000-0003-0887-9227. E-mail: olavo.soares@unifal-mg.edu.br.
} 
conceitos cotidianos sobre os números, a água, a energia, o tempo. Em sala de aula eles vão interagir com esses mesmos conceitos, mas em seus significados científicos. Assim, uma das especificidades da educação escolar é justamente a de lidar com processos de ensino e aprendizagem nos quais a vida cotidiana e os conhecimentos científicos se relacionam de modo intermitente.

A educação escolar deve desenvolver um espaço de troca de experiências que é específico: se, por um lado, ela lida com a produção de um conhecimento novo, característico da escola, por outro, ela precisa considerar que a produção desse conhecimento depende essencialmente das múltiplas mediações estabelecidas por professores e alunos. O conhecimento escolar resulta da mediação entre o que sabemos e como a ciência trata do que sabemos.

Pensar a escola nessa perspectiva significa aceitar a concepção de que a educação escolar pode e deve admitir uma didática que seja desenvolvente, ou seja: práticas de ensino que valorizem as aprendizagens dos estudantes, os seus processos de apropriação e objetivação do conhecimento, o desenvolvimento de sua autonomia e de suas capacidades psíquicas mais complexas. Nessa perspectiva, o professor deve ter um papel ativo nos processos de produção do conhecimento escolar, pois os docentes precisam ajudar os alunos a estabelecer relações entre as diferentes formas de conhecimento e de interpretação da realidade.

A defesa de uma educação escolar humanizadora envolve inúmeros aspectos das práticas escolares. Aqui, o nosso objetivo é propor uma metodologia de ensino que contribua para melhoras qualitativas nos processos de ensino-aprendizagem da história escolar. Para tanto, nos referenciamos nas teorias sobre a atividade de estudo que foram desenvolvidas no interior da perspectiva histórico-cultural.

$\mathrm{O}$ texto se divide em dois momentos. Inicialmente analisamos algumas categorias essenciais da atividade de estudos, com destaque para as tarefas de estudos, a motivação e a aprendizagem conceitual. Posteriormente, apresentamos as possibilidades de utilização deste referencial teórico-metodológico nos processos de produção do conhecimento histórico escolar, considerando a apropriação, por professores e alunos, das ferramentas básicas da produção historiográfica. 


\section{As tarefas, a motivação e os conceitos na atividade de estudo}

A elaboração de métodos de estudo é algo implícito às práticas escolares, seja na perspectiva do senso comum ou das teorias sobre a didática. Como dividir e intercalar o tempo de estudo dos alunos, bem como definir metodologias para os exercícios individuais ou em grupo é um desafio para as pesquisas em educação e para as práticas escolares.

No senso-comum sobre o ensino de história, os métodos de estudo dos alunos são recorrentemente lembrados como sendo processos de memorização. No caso brasileiro, ainda encontramos práticas de avaliação nas quais os exercícios sugeridos aos alunos são relacionados às datas, personalidades e fatos (FERNANDES; GOMES, 2018). Ao restringir a produção do conhecimento a esses três elementos, as tarefas passam a ser compreendidas como um ato individual de memorizar e retransmitir informações.

Pesquisas no campo sugerem que as práticas de memorização estão mais vinculadas a concepções historiográficas do que com a tradição escolar (BITTENCOURT, 2005). Sabemos que, embora a historiografia que se desenvolveu ao longo do século XIX tenha sido suplantada por inúmeras e inovadoras perspectivas historiográficas, suas peculiaridades em termos de organização do currículo e das práticas escolares ainda estão presentes. De fato, se analisarmos a prescrição apresentada na atual BNCC - Base Nacional Comum Curricular - (BRASIL, 2017) para o ensino de história, nós veremos a sombra de uma perspectiva historiográfica eurocêntrica, baseada no modelo quadripartite francês e que sugere práticas de ensino voltadas para a memorização.

Ao identificar que os modelos didáticos das práticas de ensino de história estão vinculados às perspectivas historiográficas, as pesquisas sobre ensino de história no Brasil voltaram suas atenções para as outras possibilidades didáticas que se identificam com perspectivas historiográficas contemporâneas e que valorizam outros processos de ensino-aprendizagem (BITTENCOURT, 2005). Nas pesquisas sobre os currículos para o ensino de história, vemos com mais nitidez esse movimento. As mudanças na prescrição curricular, notadamente após os anos 1980, são justificadas 
mais em função das modificações na historiografia do que nas pesquisas do campo da didática e dos processos de ensino-aprendizagem (FONSECA, 2003).

Este movimento de buscar proximidade com a historiografia é muito importante, porque atualiza o campo em relação às conquistas da produção de conhecimento científico sobre a história. No entanto, mantém as mesmas dificuldades no que tange às tarefas de estudo. Por exemplo, atualmente é uma unanimidade a defesa do uso das fontes históricas nos processos de ensino. No entanto, pouco se pesquisa sobre como os alunos se relacionam com as fontes; quais fontes são mais adequadas para determinadas etapas do processo formativo; quais metodologias de ensino indicam que as fontes nos auxiliam na produção do conhecimento escolar.

Em pesquisa sobre as metodologias de ensino nos livros didáticos de história para as séries iniciais, nós constatamos este paradoxo: os livros apresentam inúmeras fontes históricas que poderiam ser utilizadas para explicitar o racismo estrutural da sociedade brasileira; contudo, a forma como as fontes são metodologicamente apresentadas acabam por legitimar esse racismo (MONTEIRO; SOARES, 2019). Assim, torna-se fundamental pesquisar e justificar o uso das fontes nas práticas de ensino, afinal a análise das fontes é uma das principais características do ofício do historiador. Ou seja, ainda precisamos pesquisar mais sobre os métodos e procedimentos didáticos de seus usos nas salas de aula.

Em nossa aproximação com a perspectiva histórico-cultural e com a teoria da atividade, nós constatamos que o uso das fontes históricas no processo de produção do conhecimento é essencial para possibilitar aos estudantes "novas necessidades de conhecimento" (SOARES, 2008, p. 134). Quando utilizadas de forma adequada, ou seja, através de tarefas de estudo direcionadas a estes objetivos, as fontes despertam nos alunos indignação, alegria, revolta, compaixão, solidariedade, empatia. Sentidos que os levam a buscar mais conhecimentos, e, portanto, novas fontes.

Ao ter contato com a obra de V. V. Davídov, nós compreendemos que o uso das fontes, além de nos aproximar do ofício dos historiadores, também possibilita aos professores e alunos o desenvolvimento de um pensamento teórico sobre a história e suas formas de produção (DAVÍDOV, 1978). Nessa perspectiva, além de 
aguçar os sentidos e criar necessidades de conhecimento, as fontes exigem a formulação de perguntas e de hipóteses, o desenvolvimento da pesquisa, o pensamento abstrato, a elaboração do conceito. Nenhum desses objetivos será factível sem a elaboração de tarefas de estudo que sejam a ele compatíveis.

Segundo Elkonin, a tarefa de estudo

[...] não é apenas uma tarefa que o aluno realiza na sala de aula ou em casa. A tarefa de estudo representa um sistema completo. A resolução de um sistema de tarefas provoca a formação de modelos generalizados de resolução de outras tarefas da área estudada. (ELKONIN, 2020, p. 161).

As tarefas são a própria estrutura da atividade de estudo. Seus objetivos não podem estar desvinculados dos objetivos da atividade: a autonomia dos estudantes em relação ao conhecimento e ao seu próprio desenvolvimento. Nesse sentido, é preciso entender os estudantes, sejam crianças, adolescentes ou adultos, como sujeitos dos processos de ensino-aprendizagem: "a atividade se caracteriza somente se a criança é sujeito, agindo de forma consciente e responsável, em outras palavras, livremente. Ela não está estudando porque o professor mandou, mas porque é necessário para ela” (REPKIN, 2019, p.221). Assim, as tarefas de estudo devem ser pensadas não apenas para a assimilação ou interação com o conhecimento, mas para a transformação, apropriação e objetivação deste conhecimento, que se torna mais complexo na medida em que os estudantes, em sua trajetória escolar, transformam o conhecimento e a si mesmos.

A elaboração das tarefas de estudo exige da docência a inversão da lógica empirista que se tornou tradição nas práticas escolares (ILYENKOV, 2007). Nessa tradição, as atividades escolares são elaboradas objetivando a percepção e a representação do conhecimento, em uma concepção de ensino linear que vai do simples ao complexo, do concreto ao abstrato (DAVÍDOV, 1978).

Para subverter as práticas empiristas, precisamos modificar os modelos didáticos da disciplina: de atividades baseadas em conteúdos e conhecimentos que têm perguntas e respostas prontas, para atividades que geram perguntas, hipóteses e necessidades de novos conhecimentos. 
As tarefas de estudo devem motivar os estudantes no processo de produção do conhecimento. Na perspectiva que estamos desenvolvendo, a motivação deve ser entendida como o movimento interno que mobiliza os estudantes para o conhecimento. Não nos referimos à motivação como um ato ou ação que é exterior ao sujeito ou como algo que vá motivá-lo através de uma recompensa, como querem os comportamentalistas; ao contrário, nossa atenção está nos motivos que vinculam os estudantes às atividades escolares.

Entendemos a motivação em suas semelhanças e similaridades com a categoria motivo, tal como foi apresentada por A. Leontiev (s/d; 1978). Para esse pesquisador soviético, que contribuiu para lançar as bases teóricas da teoria da atividade de estudo, o motivo que é interno e específico a cada indivíduo, nos ajuda a compreender as relações que os seres humanos estabelecem com as diferentes atividades de sua vida (LEONTIEV, s/d; 1978).

O motivo é a incorporação consciente pelos indivíduos dos "fins" de uma determinada atividade: "aquilo para o que está orientado esse processo pode parecer o que o impulsiona, o que constitui seu motivo; se é assim, então é uma atividade" (LEONTIEV, 1978, p. 218-219, tradução nossa). Portanto, estar em atividade significa orientar-se de forma consciente nas ações que estão sendo realizadas.

Os argumentos de Leontiev provocam uma revolução nas pesquisas sobre a didática, justamente por identificar que os processos de ensino, em si, podem estar distantes das aprendizagens pretendidas. Um de seus exemplos é esclarecedor:

Os alunos do primeiro e segundo anos sabem para que estudam e em geral sabem para que têm de estudar. Porém acaso isto os obriga verdadeiramente a escutar com atenção o mestre e a cumprir com zelo suas tarefas no lar? Não, não é assim. O que verdadeiramente os impulsiona a estudar são outros motivos: é possível que desejem aprender a ler, escrever e contar; talvez queiram obter a nota mais alta; talvez queiram conservar seu prestígio em família, em classe, diante do mestre. (LEONTIEV, 1978, p. 231, tradução e grifo nossos).

Leontiev identifica que as ações que os estudantes desenvolvem nas escolas nem sempre têm no conhecimento um motivo consciente. Podem estar conscientes para os alunos as notas, o agrado aos pais e professores, a recompensa familiar. $\mathrm{O}$ 
motivo que os vincula à escola e aos processos de aprendizagens não está relacionado ao seu desenvolvimento como indivíduo e à sua inserção na sociedade através da apropriação do conhecimento.

A teoria de Leontiev sobre a atividade irá impulsionar as pesquisas sobre a didática e a atividade de estudo, justamente porque se vislumbra na constatação de Leontiev que é possível desenvolver tarefas de estudo que possibilitem a incorporação do motivo da atividade, que é a produção do conhecimento. E a chave para esse processo didático reside em outra categoria essencial da obra de Leontiev que é tributária do materialismo histórico: as necessidades (LEONTIEV, s/d; 1978).

A necessidade é o que impulsiona os indivíduos para uma ou outra atividade, e, por conseguinte, determina a incorporação do motivo. Se a necessidade do aluno é agradar os pais, suas ações caminharão com este objetivo e o motivo que encaminha a sua atividade será esse. Por outro lado, se uma tarefa de estudo for capaz de modificar essa necessidade básica do aluno, teremos então a possibilidade de surgimento de um novo motivo.

Pensemos então no motivo como o movimento interno do indivíduo que o motiva a realizar um conjunto de tarefas que compõem uma atividade de estudo de história. Neste caso, nosso primeiro desafio passa a ser conseguir transformar o conhecimento histórico em uma necessidade para os estudantes. Em nossas pesquisas, temos visto que este é o elemento mais complexo de elaboração de atividades de estudo em história: transformar as necessidades cotidianas dos alunos em necessidades de conhecimento.

Quando nos debruçamos sobre as necessidades cotidianas e práticas dos estudantes, notadamente daqueles do Ensino Fundamental II e Ensino Médio, é possível identificar necessidades distintas: não desagradar à família, socializar, se alimentar ou não ficar "na rua, sem fazer nada"; muitos estudantes do Ensino Médio têm a necessidade de se preparar para as provas e exames que permitem acesso ao Ensino Superior. Entretanto, junto a essas necessidades básicas e cotidianas, há outro conjunto de necessidades inerentes aos estudantes que são as suas emoções e desejos. 
Em uma de suas últimas publicações, Davídov (2020) argumenta que o desejo deve ser considerado como um elemento que compõe e alimenta as necessidades.

De acordo com nossas observações da vida real e segundo alguns dados científicos, entendemos que as emoções e as necessidades não podem ser consideradas por separado, pois as necessidades se mostram por meio das manifestações emocionais.

O termo desejo atinge a verdadeira essência da questão: as emoções são inseparáveis das necessidades. Ao discutir certa emoção, podemos sempre identificar a necessidade em que aquela está baseada. E, quando estamos discutindo um tipo de necessidade, temos que definir as emoções que dela se originam, para especificarmos o que foi citado acima. (Davídov, 2020, p. 292-293).

Não precisamos falar em camadas de necessidades, mas podemos identificar tipos de necessidades que são significativamente diferentes entre os estudantes: as necessidades práticas e cotidianas e aquelas vinculadas com as suas emoções e desejos. Davídov nos ajuda a sermos coerentes com a teoria vigotskiana na qual os seres humanos se desenvolvem como unidade que congrega em suas funções psíquicas superiores um grande conjunto de capacidades: a racionalidade, a emoção, a sensibilidade artística, a capacidade de abstração, a memória, a linguagem, a criatividade (VIGOTSKI, 2000; 2001).

As emoções e os sentidos que os alunos atribuem ao conhecimento histórico são elementos essenciais para o desenvolvimento das tarefas que compõem a atividade de estudo. Tais tarefas devem ajudar a aflorar os sentimentos dos alunos, considerando que eles têm necessidades de conversar, se manifestar, se indignar ou de festejar. Nas aulas de história as emoções não podem ser consideradas como sentimentos de segundo plano, mas a "porta de entrada" que irá proporcionar novas formas de conhecimento.

Até o momento, tratamos da importância da atividade de estudo para o desenvolvimento da autonomia dos estudantes em relação ao conhecimento histórico. Defendemos que as emoções e as diversas motivações dos alunos devem ser consideradas nas tarefas de estudo das aulas de história, pois são vias para o desenvolvimento de novas necessidades de conhecimento. Agora, precisamos 
apresentar o objetivo desta didática: o desenvolvimento do pensamento teórico a partir da aprendizagem e domínio dos conceitos históricos.

$\mathrm{Na}$ perspectiva que estamos desenvolvendo, e buscando coerência com o conjunto das pesquisas sobre a atividade de estudo, nós entendemos que o pensamento teórico e a aprendizagem de conceitos correspondem a uma unidade em relação ao desenvolvimento psíquico dos estudantes. A apropriação e objetivação dos conceitos dependem do pensamento teórico, e o seu oposto é igualmente verdadeiro.

Um aspecto significativo da obra de Davídov (1978) diz respeito justamente à ausência desses elementos na aprendizagem dos estudantes das escolas com didáticas tradicionais. Sua constatação é singular, e assim como em Leontiev, igualmente revolucionária: na tradição escolar, os alunos aprendem o resultado dos conhecimentos científicos, mas não desenvolvem capacidades cognitivas semelhantes às dos cientistas, pois se mantêm no nível do pensamento empírico sobre a realidade (DAVÍDOV, 1978). Na obra de Davídov, essa constatação se justifica pelas pesquisas que demonstram que a maioria dos estudantes não desenvolve uma aprendizagem sobre os conceitos científicos. Nas práticas escolares, ainda segundo Davídov (1978), os conceitos são apresentados em suas “aparências" e em suas relações com "as partes" e não na "essência" que compreende a totalidade dos fenômenos.

$\mathrm{Na}$ dependência empírica, a coisa isolada aparece como uma realidade autônoma. Nas dependências descobertas pela teoria, a coisa aparece como meio de manifestação de outra dentro de certo todo. Tal trânsito de coisa a coisa, a superação da especificidade da coisa durante sua conversão em outra, isto é, sua conexão interna, aparece como objeto do pensamento teórico. Este sempre lida com coisas reais, dadas sensorialmente, mas alcança o processo de sua mútua passagem, de sua relação dentro de certo todo e na dependência dele. (DAVÍDOV, 1978, p.307, tradução nossa).

Ao analisarmos o ensino de história em suas práticas, materiais didáticos e currículos, nós verificamos com clareza essa diferenciação entre as partes e o todo, entre o empírico e o teórico. É possível verificar também como tais práticas dificultam o desenvolvimento do pensamento teórico sobre a história e a realidade. 
Currículos e materiais didáticos induzem os professores a tratar de um mesmo conceito ao longo da trajetória da vida escolar. Por exemplo, o conceito de trabalho está presente em todas as fases da escolarização; para as crianças, pedem-se: o estudo das profissões na família; posteriormente, das diferenças entre o trabalho escravo e o assalariado; do trabalho no contexto da imigração; do trabalho nas fábricas; da atualidade do trabalho. $\mathrm{Na}$ forma de sua apresentação, não temos a essência do conceito. O trabalho surge como uma "coisa isolada", "aparece como uma realidade autônoma" (DAVÍDOV, 1978, p. 307, tradução nossa). Como o conceito está em séries e anos diferentes, temos a aprendizagem das suas aparências, de suas características exteriores, não da sua essência, o que define o conceito de trabalho.

Por outro lado, “a superação da especificidade da coisa durante sua conversão em outra, isto é, sua conexão interna, aparece como objeto do pensamento teórico" (DAVÍDOV, 1978, p. 307, tradução nossa). Caso o conceito de trabalho fosse a base para o seu estudo nas diferentes etapas da escolarização, os estudantes poderiam recorrer sempre ao todo e abstrair sobre as partes. A própria definição do conceito exige um pensamento que se distancia do empírico. "Este sempre lida com coisas reais, dadas sensorialmente, mas alcança o processo de sua mútua passagem, de sua relação dentro de certo todo e na dependência dele" (DAVÍDOV, 1978, p. 307, tradução nossa). Na atividade de estudo, o sensorial e perceptível é uma descoberta dos estudantes, e não um dado pronto apresentado pelo professor.

O que temos defendido é que nas práticas de ensino de história a aprendizagem dos conceitos seja a base que deve estruturar a elaboração de currículos e materiais didáticos. Como vimos, é na aprendizagem conceitual que ocorre o desenvolvimento do pensamento teórico, pois "o conceito é o meio de reprodução e estruturação mental do objeto" (DAVÍDOV, 1978, p. 359, tradução nossa).

Sabemos de nossas dificuldades nestas proposições. A principal delas está relacionada à própria definição sobre os conceitos históricos que se originam como fruto do debate historiográfico. A história, assim como as demais ciências humanas, tem uma especificidade que as diferencia dos demais campos da 
ciência: são seres humanos pesquisando sobre outros seres humanos, e não sobre animais, fórmulas, cálculos ou materiais inorgânicos. Esta particularidade da ciência histórica explica a variabilidade e a mutabilidade dos conceitos ao longo da história da humanidade. Davídov compreendia essas especificidades e defendia que os conceitos históricos na escola precisam incorporar, no estudo da sua essência, essa mutabilidade (DAVÍDOV, 1978).

Outra dificuldade está relacionada ao fato de que a maioria das pesquisas e relatos de experiência no campo da atividade de estudo está relacionada às séries iniciais dos processos de escolarização. No caso brasileiro, há nos currículos oficiais a inserção do conhecimento histórico nas séries iniciais. No entanto, seja em função dos processos de formação de professores ou da excessiva importância dada às avaliações sistêmicas, o ensino de história nas séries iniciais é relegado ao segundo plano. Em função desses fatores e da nossa experiência docente na escola básica e na formação de professores da área de história, nossas pesquisas se desenvolvem tendo como foco os níveis do Ensino Fundamental II e Médio.

Nas linhas que seguem, nós iremos apresentar alguns princípios que consideramos básicos para o desenvolvimento da atividade de estudo nas práticas de produção do conhecimento histórico escolar.

\section{A atividade de estudo nas aulas de história e sua viabilidade}

Nas tarefas de estudo, temos como premissa básica que, na interação com os objetos do conhecimento, os estudantes transformem a si, e não apenas o objeto (ELKONIN, 2020; REPKIN, 2019). Nesse movimento, é imprescindível que as emoções e sentimentos sejam considerados como aspectos das necessidades básicas dos alunos: o afeto, o diálogo, as amizades, o carinho, a empatia; e considerar também o oposto, que são interiorizados como desrespeito, racismo, revolta, falta de empatia. As emoções dos estudantes apresentam indícios de suas relações com a sociedade e com o conhecimento histórico.

O objetivo das primeiras tarefas deve ser conhecer essas necessidades dos alunos e permitir que eles apresentem seus sentimentos e exponham suas formas de compreensão e interpretação sobre determinados elementos da realidade. Ao 
professor de história cabe orientar sobre o conhecimento histórico a ser analisado e qual será o objeto da aprendizagem conceitual. As necessidades iniciais são dos estudantes, mas é o professor quem deve definir qual o conceito a ser elaborado em função das etapas de aprendizagem de cada série ou turma.

Vamos exemplificar esse movimento. Para tanto, utilizaremos o conceito de indústria cultural, que está presente nos currículos para o ensino de história no Ensino Fundamental II e Médio.

As primeiras tarefas devem ser dedicadas a compreender como a indústria cultural está presente na vida dos alunos e como se vincula às necessidades básicas deles. Por exemplo: o professor leva para a sala de aula alguns "memes" ou "paródias" que foram intensamente divulgadas nas redes sociais durante a semana. De preferência, algo que ele já saiba ser do conhecimento dos alunos. Neste movimento será possível perceber como os alunos se relacionam em sala, qual a idade psicológica da turma, quais interesses culturais e de relacionamento social eles têm, como veem e percebem as relações entre as informações das redes sociais e da escola.

Despertadas e socializadas as necessidades básicas, temos um terreno mais fértil para o desenvolvimento de novas necessidades, necessidades de conhecimento (SOARES, 2008). Como afirma Repkin (2019), este pode ser um movimento dolorido para alunos e professores, afinal ao desestabilizar os conhecimentos empíricos e cotidianos, os alunos ficam incomodados.

Um segundo bloco de tarefas pode começar com perguntas provocativas, por exemplo: são vocês que procuram nas redes sociais o que lhes interessa ou são as redes que conduzem seus gostos e sentimentos?

Essa pergunta, se bem realizada pelo professor, pode encaminhar as seguintes ações mentais dos alunos: exigir posicionamentos, levantar hipóteses, buscar informações e exemplos, pesquisar se esse é um fenômeno apenas do presente ou se é também histórico. É um movimento que exige o pensamento abstrato, e como afirma Davídov (1978), o abstrato não elimina o concreto; a busca da essência do conhecimento, o seu conceito, não prescinde da interpretação sobre sua aparência. 
É tarefa do professor auxiliar os alunos nesse processo interpretativo. Pode começar demonstrando aos alunos que embora as redes sociais por meio digital sejam uma novidade do ponto de vista tecnológico, a sua essência enquanto indústria cultural nos remete à primeira metade do século XX. Vale lembrar que essa intervenção do professor não deve ser realizada na forma de uma aula expositiva, do professor para os alunos, mas junto com os alunos.

Para fazer esse movimento interpretativo, o professor pode levar para a turma fragmentos das pesquisas realizadas por Theodor Adorno, expoente da Escola de Frankfurt, sobre o rádio nos Estados Unidos nos anos 1930 (CARONE, 2019). Nestas, foi demonstrado como as rádios cativavam a audiência ao se antecipar aos likes e dislikes dos ouvintes. Para identificar os gostos dos ouvintes e se antecipar ao que seria um sucesso musical, as emissoras de rádio faziam surveys semelhantes aos que as redes sociais fazem atualmente ${ }^{2}$.

Por ser uma atividade de estudo da história é fundamental que o professor mobilize fontes históricas de pesquisa e análise. Por exemplo, na análise da influência da indústria cultural na disseminação e formação dos gostos musicais, é possível pesquisar sobre diferentes tempos e espaços: a beatlemania nos Estados Unidos dos anos 1960, o axé e o pagode no Brasil dos anos 1990, o sertanejo e o funk no Brasil contemporâneo.

Nestas tarefas, é importante verificar se os alunos estão em atividade, ou seja, se eles conseguem compreender que um determinado fenômeno não está congelado no passado, mas está presente na vida cotidiana deles e apresenta transformações e permanências que se relacionam com aspectos da atual vida em sociedade. Afinal, a atividade de estudo deve ter este objetivo: modificar o sujeito e a sua relação com o mundo.

Como nos adverte Repkin, não é um processo fácil:

Sentir-se um ser humano e não um dente em uma engrenagem não é uma coisa tão agradável. É um sentimento que está associado com sofrimento agudo. $\mathrm{O}$ sujeito encontra-se em uma situação de escolha

\footnotetext{
2 Sobre a manipulação de dados nas redes sociais, ver os seguintes documentários: a) Privacidade Hackeada. Direção de Karim Amer e Jehane Noujaim. Roteiro de Karim Amer e Pedro Kos, 2019; b) O Dilema das redes. Direção de Jeff Orlowski. Roteiro de Jeff Orlowski, Davis Coombe, Vickie Curtis. 2020.
} 
relacionada à personalidade: ou tomar o caminho mais fácil para resolver a tarefa ou parar e começar a tentar melhorar a si mesmo, buscar uma razão. (REPKIN, 2019, p. 233).

Um bom e adequado estudo da história deve ser exatamente isto: um incômodo. Não é fácil verificar que nossos sentimentos mais íntimos estão sempre relacionados aos processos históricos, que nossos gostos, vontades e desejos não estão separados do contexto histórico em que vivemos. Viver na contramão não é fácil, pois a sociedade brasileira contemporânea prega justamente o contrário: que o sucesso ou fracasso dos sujeitos se explica por sua individualidade. Estar na contramão dessa pregação ideológica é um dos papéis e funções da história.

Ao verificar como os estudantes interpretam e analisam as fontes, o professor pode avaliar se eles estão em processo de aprendizagem conceitual. Para tanto, é preciso que estejam desenvolvendo autonomia em relação ao conhecimento: a capacidade de acionar informações, fontes e conhecimentos diversos para formular uma síntese do conceito. Um conjunto de tarefas deve se dedicar a este movimento: à apropriação de uma questão específica e à objetivação das hipóteses dos estudantes. Neste caso, a questão é: o que define a indústria cultural?

A verificação das aprendizagens passa por outro conjunto de tarefas: a assimilação dos conceitos através de pesquisas elaboradas pelos próprios estudantes (REPKIN, 2019). Para que essas pesquisas sejam tarefas de estudo, o professor precisa ajudar os alunos a organizar as suas perguntas e hipóteses. A definição sobre tempos e espaços a serem pesquisados deve ser dos alunos que contam com o auxílio do professor em função de sua maior experiência e conhecimento do currículo.

$\mathrm{Na}$ socialização das pesquisas, o professor poderá ajudar os alunos a ampliar sua compreensão do conceito. Se o conceito de indústria cultural ajuda os estudantes a compreender tempos e espaços distintos, bem como aspectos da contemporaneidade, a finalização da atividade os levará a outras necessidades de conhecimento. É possível que os estudantes queiram analisar o conceito de alienação, as diversas formas de relação dos sujeitos com a indústria ou a cultura 
juvenil em tempos de hiperexposição midiática. Se a turma chegar a esse nível de abstração, poderemos concluir que a atividade foi satisfatória.

Teremos, então, nos aproximado das proposições apresentadas por pesquisadores da atividade de estudo e que tem em Davídov e Márkova (2019) uma síntese:

os estudantes aprendem gradualmente a buscar, em primeiro lugar, frente a um problema particular, o princípio geral de solução de problemas semelhantes, dirigindo-se a diferentes fontes de conhecimentos para identificar este princípio, preocupar-se com a autodidática etc. A atividade de estudo está justamente orientada a formar nos alunos este tipo de pensamento teórico. (Davídov; Márkova, 2019, p. 204).

Todas as aulas de história deveriam estar baseadas nos princípios da atividade de estudo. A cada tarefa, o problema particular irá ficar mais complexo, assim como as fontes de conhecimento. Espera-se que a atividade modifique os alunos e professores internamente, em suas formas de pensar e se relacionar com a história e com a sociedade. Esperamos também que o conhecimento escolar seja elaborado e assumido pelos estudantes como fonte para o seu desenvolvimento.

Nenhuma disciplina escolar deve apartar-se dos interesses e necessidades dos alunos. Principalmente a história, que lida com a vida dos seres humanos no tempo e em sociedade. O que nos diferencia de outras perspectivas didáticas é que defendemos os interesses e necessidades de desenvolvimento dos alunos, e não a adaptação deles ao consumo e ao mercado de trabalho. Não temos dúvida de que a história e a produção de seu conhecimento, na perspectiva da atividade de estudo, permitem aos estudantes sentirem-se mais humanos.

\section{Breves considerações}

Pesquisar sobre a atividade de estudo exige de nós um exercício de revisão de paradigmas. Afinal, a educação escolar que conhecemos e com que convivemos por mais de doze anos de nossas vidas foi moldada em séculos de empirismo e de lógica formal. Nessa tradição escolar, ainda persiste a ilusão de que os estudantes aprendem o que os professores ensinam, de que se os 
alunos fizerem os exercícios solicitados eles irão compreender a matéria, de que a preparação para a vida em sociedade está relacionada às habilidades das profissões e do mercado de trabalho.

Mudar os paradigmas implica saber que os alunos compreendem, aprendem e se apropriam se houver uma relação entre os interesses pessoais e o conhecimento escolar. Denominamos esses interesses de necessidades, e a sua direção rumo ao conhecimento como motivo, ou àquilo que o motiva ao conhecimento.

As modificações nesses paradigmas devem fazer parte dos processos de formação inicial e continuada dos professores. A busca por autonomia em relação ao conhecimento deve ser o principal valor da atuação pessoal e profissional dos professores. Se os professores não pensam de forma autônoma, eles não terão condições de desenvolver atividades de estudo da história para seus alunos. Isto ocorrerá porque a atividade de estudos não é uma metodologia a ser aplicada, mas um princípio didático que inverte a lógica da tradição escolar: as atividades começam compreendendo os estudantes em suas emoções, sentimentos, e, sobretudo, em seus conhecimentos da vida em sociedade. Ao conhecer as necessidades dos estudantes, o professor pode possibilitar novas necessidades de conhecimento.

Como já afirmamos, apresentamos aqui um estudo introdutório. Ainda há muito que pesquisar sobre a atividade de estudo da história.

Precisamos de mais pesquisas teóricas sobre o papel do conceito na formulação da atividade. Na história, assim como nas demais ciências, o conceito está impregnado de mutabilidade e o próprio processo histórico exige que o conceito se modifique. A cada mudança na história, há modificações nos conceitos. O conceito de indústria cultural, como apresentado aqui, por exemplo, não é uma primazia da chamada Escola de Frankfurt. Outros teóricos analisaram e deram definições diversas a esse conceito, assim como sabemos que o conceito foi e ainda é objeto de questionamento de inúmeros teóricos.

Compreendemos que a unidade conceitual da atividade de ensino de história é o estudo da humanidade em tempos e espaços diversos, em suas 
transformações e permanência. No entanto, essa unidade conceitual tem na historiografia uma ramificação quase infinita de formulações conceituais.

Necessitamos também de pesquisas que analisem as diferenças entre as atividades de estudo para crianças, adolescentes e jovens. Enquanto para as crianças as atividades tendem a se aproximar da unidade a humanidade no tempo, as atividades para adolescentes visam a se aproximar da diversidade de conceitos dentro da unidade, ou seja, do estudo dos conceitos que auxiliam a compreensão da humanidade no tempo.

É importante também desenvolver pesquisas sobre o uso das fontes históricas nas atividades de estudo e sobre as aproximações entre as ações de estudo com o ofício do historiador. Não há dúvida de que o uso das fontes é essencial para o desenvolvimento das atividades de estudo. Porém, precisamos pesquisar sobre como a sua utilização se transforma em ações que aproximem os estudantes da pesquisa historiográfica e da própria formulação de conceitos históricos. Na atividade de estudo, não queremos mini-historiadores, mas estudantes que compreendam como a história científica e acadêmica é produzida, que saibam identificar produções de fake news sobre a história, que se desenvolvam no sentido de identificar a diferença entre a história e suas narrativas e representações.

Parafraseando Ilyenkov (2007, p. 49), sem esse movimento, teremos acesso a produções historiográficas altamente sofisticadas e inovadoras, mas com métodos de ensino que não nos diferenciam do empirismo de Locke e Comenius.

\section{Referências}

BITTENCOURT, Circe M. F. O ensino de história: fundamentos e métodos. São Paulo: Cortez, 2005.

BRASIL. Base Nacional Comum Curricular. Brasília: MEC, 2017.

CARONE, Iray. Adorno em Nova York: Os estudos de Princeton sobre a música no rádio (1938-1941). São Paulo: Alameda, 2019.

DAVÍDOV, Vasily V. Tipos de generalización en la enseñanza. Habana: Editorial Pueblo y Educación, 1978. 
DAVÍDOV, Vasily V. Uma nova abordagem para o entendimento e estrutura da atividade. In: AMORIM, Paula A. P.; CARDOSO, Cecília G. C.; PUENTES, Roberto V. (org.). Teoria da atividade de estudo: contribuições de D. B. Elkonin. V. V. Davídov e V. V. Repkin. Uberlândia: EDUFU, 2020.

DAVÍDOV, Vasily V; MÁRKOVA. A. A concepção de atividade de estudos dos alunos. In: MELLO, Sueli. A.; PUENTES, Roberto V. (org.). Teoria da atividade de estudo. Livro II. Contribuições de pesquisadores brasileiros e estrangeiros. Uberlândia: EDUFU, 2019.

ELKONIN, D. B. Estrutura da atividade de estudo. In: AMORIM, Paula A. P.; CARDOSO, Cecília G. C.; PUENTES, Roberto V. (org.). Teoria da atividade de estudo: contribuições de D. B. Elkonin. V. V. Davídov e V. V. Repkin.

Uberlândia: EDUFU, 2020.

FERNANDES, Alex de Oliveira; GOMES, Suzana dos Santos. Interfaces entre Avaliação e Currículo de História no Ensino Médio. Educação e Realidade. Porto Alegre. v. 43, n. 4. p. 1363-1384, 2018.

FONSECA, Selva Guimarães. Caminhos da história ensinada. Campinas: Papirus, 2003.

ILYENKOV, Evald V. Our Schools Must Teach How to Think! Journal of Russian and East European Psychology, vol. 45, no. 4, 2007.

LEONTIEV, A. O desenvolvimento do psiquismo. São Paulo: Moraes, s.d.

LEONTIEV, A. Actividad, conciencia y personalidad. Buenos Aires: Ediciones Ciencias del hombre, 1978.

MONTEIRO, Juliana R. M.; SOARES, Olavo P. De boas intenções o inferno está cheio: as metodologias de ensino nos livros didáticos de história. História \& Ensino, Londrina, v. 25, n. 1, 2019.

REPKIN, V. V. Ensino desenvolvente e atividade de estudo. In: MELLO, Sueli. A.; PUENTES, Roberto V. (org.). Teoria da atividade de estudo. Livro II. Contribuições de pesquisadores brasileiros e estrangeiros. Uberlândia: EDUFU, 2019.

SOARES, Olavo P. A atividade de ensino de história: processo de formação de professores e alunos. Araraquara, SP: Junqueira \& Marin, 2008.

VIGOSTKI, Lev S. Génesis de las funciones psíquicas superiores. In: VIGOSTKI, Lev S. Obras escogidas III. Madrid: Visor, 2000, p.139-168.

VIGOSTKI, Lev S. A construção do pensamento e da linguagem. Trad. Paulo Bezerra. São Paulo: Martins Fontes, 2001. 